\title{
Assessment of systolic and diastolic cycle duration from speech analysis in the state of anger and fear.
}

\author{
Nivedita Deshpande ${ }^{1}$, Dr. KavitaThakur ${ }^{2}$, Prof. A.S.Zadgaonkar ${ }^{3}$, \\ ${ }^{1}$ School of Study Electronics, Pt. Ravishankar University, Raipur, \\ Chhattisgarh, India \\ ${ }^{2}$ Reader, School of Study in Electronics,Pt. Ravishankar University, Raipur, \\ Chhattisgarh, India \\ ${ }^{3}$ Vice Chancellor, Dr. C.V. Raman University,Bilaspur, Chhattisgarh, India
}

\begin{abstract}
:
An electrocardiogram (ECG) is a test that records the electrical activity of the heart. ECG is also used to measure the rate and regularity of heart beats and can be correlated to blood pressure measurement. This paper describes a technique of the determination of systole and diastole cycle duration from the RR-cycle using speech parameters. The formant F2 and F3 characterize different emotional states like anger and fear. One heart beat includes one systole and one diastole cycle. In an electrocardiogram, electrical systole of the ventricles begins at the beginning of the QRS complex. Diastolic variation occurs after the systole cycle. RT interval describes systole cycle duration. The ECG, and the speech sample of several informants have been recorded simultaneously to obtain the required relationship.
\end{abstract}

\section{Key words :}

Formant Frequency, RR-Cycle, Systole cycle, Diastole cycle

\section{INTRODUCTION}

As the formant frequencies reflect the intricate features like physical or psychological features of human body[1,2,3]. The formant analysis can provide useful information about our important body organs like brain, heart, nervous system[3,4,6,] . F2 and F3 formant frequencies reflect the anger and fear emotional states. [1,2,4].

A. Background : As previous work has been done to determine the RR-cycle in the state of anger and fear[2]. Previous work describes the heart beat feature extraction from vowel speech signal [4].

Natarajan Meghanathan, et al. (Eds): ITCS, SIP, JSE-2012, CS \& IT 04, pp. 137-141, 2012.

(C) CS \& IT-CSCP 2012

DOI : $10.5121 /$ csit.2012.2112 


\section{B. Blood Pressure}

Our heart pumps the blood in our body with some pressure[3,4]. Blood pressure (BP) is the pressure exerted by circulating blood upon the walls of blood vessels and is one of the principal vital signs. When used without further specification, "blood pressure" usually refers to the arterial pressure of the systemic circulation. During each heartbeat, BP varies between a maximum (systolic) and a minimum (diastolic) pressure.

Heart contracts to achieve a maximum blood pressure as required for proper circulation in our body. This pressure is called systolic blood pressure and the duration is called systole cycle. After the systole cycle completed the heart comes in the relaxing position by exerting minimum blood pressure called diastolic blood pressure. This resting period of heart is called diastole cycle. The systole and diastole cycle duration make one RR cycle duration $(0.8 \mathrm{sec}$.$) .$

Electrocardiogram (ECG) is a measure of the functioning of human heart The ECG pattern comprises of P, Q, R, S \& T components as shown in the lower curve in Fig1.[1] .Since one RR cycle has duration of $(0.6-0.8)$ sec. in normal persons at rest. And the heart beats @ 60-80 beats per min $[7,8]$.

Cardiac cycle $(0.8 \mathrm{sec})$ can be divided into three stages as follows-

1. diastole (relaxation $0.6 \mathrm{sec}$ )

2. atrial systole (contraction of atria $0.06 \mathrm{sec}$ )

3. ventricular systole (contraction of ventricals $0.2 \mathrm{sec}$ )

In an electrocardiogram electrical systole of the ventricles begins at the beginning of the QRS complex. Cardiac Diastole is the period of time when the heart relaxes after contraction in preparation for refilling with circulating blood. Ventricular diastole is when the ventricles are relaxing, while atrial diastole is when the atria are relaxing. Together they are known as complete cardiac diastole[ $[7,8]$.

During ventricular diastole, the pressure in the (left and right) ventricles drops from the peak that it reaches in systole. When the pressure in the left ventricle drops to below the pressure in the left atrium, the mitral valve opens, and the left ventricle fills with blood that was accumulating in the left atrium.

The standard ECG along with Blood Pressure waveform is shown in Fig. 1. 
Fig 1. Standard ECG with blood pressure waveform[9]

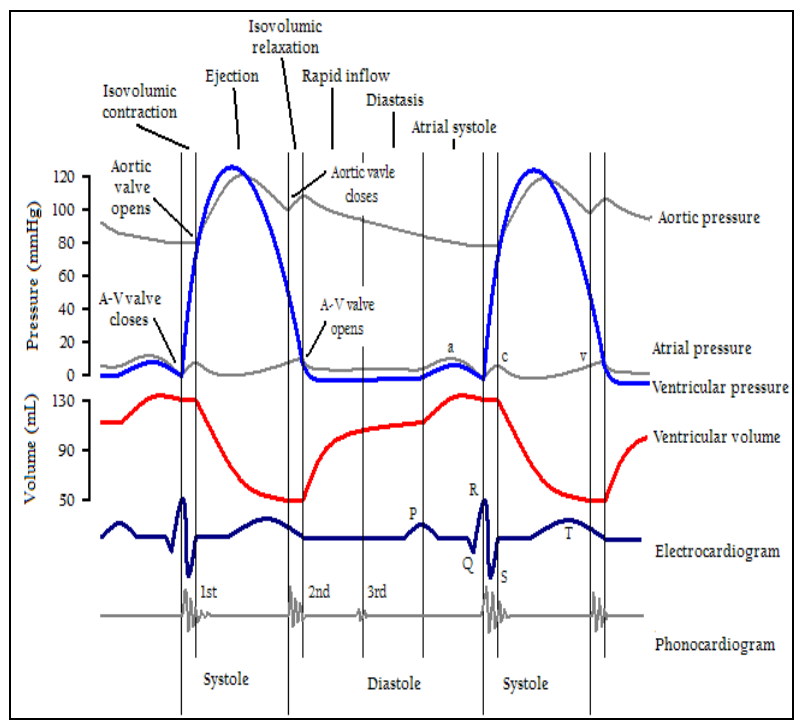

\section{METHODOLOGY}

The ECG of the several informants have been recorded. At the same time the utterances of Hindi consonants of same informants were recorded through a microphone and subjected to digitization. Further the formant frequency analysis has been carried out with a DSP Tool (PRAAT) to obtain the various formant frequencies [2] and F1, F2 and F3 formant frequency vs utterances duration response is plotted to observe the RR-cycle in the state of anger and fear[4,10-15] .

Since QRS complex corresponds to the systolic cycle \& RT interval describes diastolic cycle[7,8]. The observation table ,TABLE I provides the systolic and diastole cycle duration in the normal state and in the state of anger and fear.

TABLE I. Determination of diastole and systole duration from RR-cycle

\begin{tabular}{|l|l|l|l|l|l|l|l|l|l|l|l|}
\hline $\begin{array}{l}\text { S. } \\
\text { N. }\end{array}$ & $\begin{array}{l}\text { Age } \\
\text { Yrs }\end{array}$ & $\begin{array}{l}\text { Medical } \\
\text { Conditi } \\
\text { on }\end{array}$ & \multicolumn{2}{l|}{$\begin{array}{l}\text { RR cycle in } \\
\text { Different mental states } \\
(\mathrm{sec})\end{array}$} & \multicolumn{3}{l|}{$\begin{array}{l}\text { Systole cycle in } \\
\text { Different mental states } \\
(\mathrm{sec})\end{array}$} & \multicolumn{2}{l|}{$\begin{array}{l}\text { Diastole cycle in } \\
\text { Different mental states } \\
(\mathrm{sec})\end{array}$} \\
\hline & & $\begin{array}{l}\text { Nor } \\
\text { mal }\end{array}$ & Anger & Fear & $\begin{array}{l}\text { Nor } \\
\text { mal }\end{array}$ & Anger & Fear & $\begin{array}{l}\text { Norm } \\
\text { al }\end{array}$ & Anger & Fear \\
\hline 1 & 25 & Normal & .89 & .75 & .74 & .29 & .29 & .28 & .60 & .46 & .46 \\
\hline 2 & 32 & Normal & .76 & .70 & .69 & .26 & .27 & .27 & .50 & .43 & .42 \\
\hline 3 & 34 & Normal & .75 & .69 & .68 & .25 & .25 & .27 & .50 & .44 & .41 \\
\hline 4 & 23 & Normal & .85 & .80 & .60 & .28 & .26 & .29 & .59 & .54 & .31 \\
\hline 5 & 34 & Normal & .82 & .78 & .72 & .29 & .26 & .29 & .53 & .52 & .43 \\
\hline
\end{tabular}




\section{RESULT \& CONCLUSION}

From the observations it becomes possible to determine the diastole and systole duration from the RR- cycle through speech parameter in the state of anger and fear. The present work provides the variation in systole and diastole duration in the state of anger and fear. As the physiological study shows that the anger and fear emotions can be dangerous for heart up to some extent. The proposed framework provides the facility to observe the effect of anger and fear on the heart .

\section{ACKNOWLEDGEMENT}

Authors are very much thankful to all the informants ,doctors and the people who have been directly or indirectly involved in writing this paper.

\section{References:}

[1] Jacob Benesty, "Springer handbook of speech processing", Springer's publication, 2008, Page 511512.

[2] Deshpande Anjali, Zadgaonkar A.S. \& Thakur K., "Determination of heart beat rate form the formant frequency analysis", NSA India (2007).

[3] Zadgaonkar A.S. \& Thakur K., Formant frequency analysis of mentally retarded, International Symposium on Frontiers of Research on Speech \& Music(FRSM2006), Lucknow, U.P., India, p3135 (2006).

[4] Neeta Tripathi(2006), Study of face and speech parameters and identification of their relationship for emotional status recognition. Ph.D. Thesis, Pt.R.S.S.U.

[5] Berstein A. \& Cohen A, “Speech processing applied for chest diagnosis, 14'th conv. Of Elect. \& Electronics Engg", Tel Aviv, Israel, p2.4.4 (1985).

[6] Marleen H.Schut, Kees Tuinenbreijer, Egon L. Vanden Brock, Joyce H.D.M. Westerink ,'Biometrics for emotion detection (BED): exploring the combination of speech and ECG", B-Interface -2010, pp 59-66.

[7] Friedberg Charles K., "Diseases of the Heart”, Saunders Pub. (1966).

[8] 1. Atray S. P., Indian Psychology, The International Standard Publication, Varanasi, P.376, (1962).

[9] Leslie Cromwell, Fred J. Weibell, Erich A. Pfeiffer," Biomedical Instrumentation and Measurements", Second Edition, PHI of India, 1977.

[10] L.J.M. Mulder, Measurement and analysis methods of heart rate and respiration for use in applied environments , Biological psychology, Vol. 34, Issue 2-3, Nov 1992, Page 205-236.

[11] Dmitrity E. Skopin, Sergey U. Baglikov, “ Heart beat feature extraction from vowel speech signal using 2D spectrum representation.”, ICIT-2009. 
[12] C.Schubert, M. Lambertz, R.A. Nelson, W. Bardwell, J.B. Choi, J.E. Disdale,” Effects of stress on heart rate complexity - A comparison between short term and chronic stress", Biol Psychol, 2009, 325-332.

[13] R.F. Orlikoff, R.J. Baken, "Fundamental frequency modulation of the human voice by the heart beat: preliminary results and possible mechanisms.”, Journal of Aco. So. America, 1989, pp 883-93.

[14] L.Scherwitz , L.E. Graham, G. Grandits, J. Billings, " Speech characteristics and coronary heart disease incidence in the multiple risk factor intervention trial.”, J.Behav Med., 1990,pp75-91.

[15] V. Gemignani, Bianchini, E. Faita, F. Giannoni, M. Pasanisi, E Picano," Assessment of cardiologic systole and diastole duration in exercise stress tests with a transcutaneous accelerometer sensor.", Computers in Cardiology, 2008, 153-156 